Espacio, Tiempo y Forma, Serie VII, H. ${ }^{a}$ del Arte, t. 18-19, 2005-2006, págs. 77-83

\title{
Nuevas aportaciones a la Juno de Alonso Cano: su procedencia y reinterpretación en la obra de Juan Antonio de Frías y Escalante
}

\section{New Information on Alonso Cano's Juno: Its Provenance and Reinterpretation in the Work of Juan Antonio de Frías y Escalante}

\author{
José Luis Requena Bravo de LagunA*
}

\begin{abstract}
RESUMEN ABSTRACT
El presente artículo viene a demostrar como la Juno de Alonso Cano perteneció primero a la colección de Margarita Cajés,

hija del pintor madrileño Eugenio, $y$ posteriormente a su viudo, Don José de

Cisneros, y cómo tras su muerte fue adquirida en pública almoneda (1665) por el pintor cordobés Juan Antonio de Frías y

Escalante (1633-1669). Asimismo, el pintor cordobés transcribió con innegable fidelidad el modelo de la Juno en su San

José con el Niño, San Juanito, $y$ dos ángeles, del Museo de Bellas Artes de Asturias, Oviedo.

This article sheds new light on the provenance of the famous painting by Alonso Cano representing the roman goddess Juno, that once belonged to the collection of Margarita Cajés. Futher research shows that it is the same work purchased in 1665 by the Spanish painter Juan Antonio de Frías y Escalante (16331669). In fact, the young painter has faithfully transformed the enigmatic goddess into a new composition representing Saint Joseph and the Christ child, now at the Museo de Bellas Artes de Asturias, in Oviedo.
\end{abstract}

\footnotetext{
* Vicerrectorado de Patrimonio, Infraestructuras y Equipamiento. Universidad de Granada.
} 
PALABRAS CLAVE

Pntura barroca, Pintura granadina, Pintura sobre lienzo, Iconografía; Mitología; Juno; Coleccionismo; Almoneda.

\section{IDENTIFICADORES}

Cano, Alonso; Frías y Escalante, Juan Antonio de; Cajés, Margarita; Cisneros, José; Museo de Bellas Artes de Asturias

(Oviedo).

\section{TOPÓNIMOS}

Granada, Madrid, Oviedo.

\section{KEY WORDS}

Baroque painting; Spanish Baroque

Painting; Oil on canvas; Iconography; Mythology; Juno.

\section{IDENTIFIERS}

Cano, Alonso; Frías y Escalante, Juan Antonio de; Cajés, Margarita; Cisneros, José; Museo de Bellas Artes de Asturias (Oviedo).

\section{PLACE NAMES}

Granada, Madrid, Oviedo.

\section{PERIOODO PERIOD \\ Siglo XVII. 17th century.}

Es sin duda el pintor cordobés Juan Antonio de Frías y Escalante (c. 16331669) uno de los más fieles intérpretes del neovenecianismo imperante en la Corte durante el segundo tercio del siglo XVII importado por Herrera el Mozo tras su estancia romana, y uno de los más dotados artistas de esa malograda segunda generación de pintores madrileños discípulos de Carreño y Rizi. Su obra ha sido estudiada por diferentes autores, intentando explicar su filiación con modelos canescos ${ }^{1}$, y sobre todo su extraordinaria habilidad, para interpretar la exuberancia y la opulencia rubeniana con el colorido vibrante y transparente de recuerdo veneciano $^{2}$. Precisamente en su producción el gusto por el neomanierismo y la teatrali-

1 En enero de 1638 Alonso Cano es llamado por el Conde Duque de Olivares para trabajar al servicio de Felipe IV en la Corte como «pintor y ayudante de Cámara» comenzando así una prolongada y fructífera etapa madrileña que tendrá un decisivo y profundo impacto en el hacer artístico de la segunda generación de pintores barrocos madrileños.

2 Para Escalante véase las aportaciones de LAFUENTE FERRARI, E.: «Escalante en Navarra y otras notas sobre el pintor», Príncipe de Viana, núm. 4 (1941), pp. 8-31; BUENDÍA, J.R.: «Sobre Escalante», Archivo Español de Arte, núm. 43, 1970, pp. 33-50 y del mismo autor «Recordatorio de Escalante en los trescientos años de su muerte», Goya, núm. 99 (1970), pp. 146-153; VALDIVIESO GONZÁLEZ, E.: «Dos pinturas inéditas de Escalante», Boletín Valladolid, 1971, pp. 495-496; GUTIÉRREZ PASTOR, I.: «Don Juan Miguel de Mortela y el origen de la Inmaculada de Escalante de las M.M. Benedictinas de Lumbier», Príncipe de Viana, Primer Congreso General de Historia de Navarra, Anejo 11, 1998, pp. 229-234; DÍAZ PADRÓN, M.: «Miscelánea de pintura barroca de la escuela de Madrid: Van der Hamen, Alonso de Arco, Escalante y J. S. Navarro», Goya, núm. 262 (1998), pp. 49-54. Más recientemente véanse DEL- 
dad en los gestos no pasa inadvertida en sus modelos y este aspecto también presente en la pintura de su maestro Francisco Rizi, no permaneció ajeno a la historiografía artística, pues el propio Palomino cuenta que Escalante «tenía afición a Tintoretto, y Veronés, porque sigue en todos aquel estilo en la composición y gracia de actitudes»3. Sin embargo, las últimas investigaciones sobre el pintor revelan una manifiesta admiración hacia los modos —clásicos e intimistas- de Alonso Cano que será una constante en su breve pero brillante trayectoria artística ${ }^{4}$.

El presente trabajo plantea un doble objetivo, demostrar como la Juno de Alonso Cano $^{5}$ (Fig. 1) fue adquirida por Escalante en la almoneda de las pinturas de José de Cisneros en 1665, y como reinterpretó el modelo de la diosa romana en su San José con el Niño, San Juanito y dos ángeles ${ }^{6}$, (Fig. 2) del Museo de Bellas Artes de Asturias, firmado y fechado en 1665.

En este sentido, la primera referencia documental que tenemos sobre la Juno de Cano la encontramos en el inventario de bienes de Margarita Cajés, hija del pintor Eugenio, donde se mencionan «dos lienços de media bara de ancho y bara $y$ sesma de alto, originales de Cano, la una de Pallas y la otra de Apolo»?.

GADO MARTÍNEZ, N.: «Juan Antonio de Frías y Escalante (1633-1699), Cuadernos de Arte e Iconografía, núm. 20 (2001), pp. 223-341 y de la misma autora «Una pintura de Escalante en Cardiel de los Montes», Archivo Español de Arte, núm. 308 (2004), pp. 428-432 y finalmente AGÜERA ROS, J.C.: «Un cuadro de Escalante del «Descanso de la Sagrada Familia», firmado y fechado en 1667», Goya, núms. 313-314 (2006), pp. 251-256.

3 PALOMINO DE CASTRO Y VELASCO, A.: Vidas, Edición de Nina Ayala Mallory, Madrid, Alianza Forma, 1986, pág. 135.

4 DELGADO MARTÍNEZ, N.: Op. Cit., pp. 235-236. La autora destaca la influencia del maestro granadino en algunas obras atribuidas a Escalante como la Anunciación de la Hispanic Society de Nueva York, firmada en 1663 muy semejante en composición y estilo a la homónima obra de Cano del retablo de Nuestra Señora de la Paz, en la iglesia de la Magdalena de Getafe, de 1645. También el Jesucristo con la Samaritana del Museo Nacional de San Telmo en San Sebastián sigue el mismo asunto que llevó a cabo Cano hacia 1650-1652, actualmente en la Rea Academia de Bellas Artes de San Fernando de Madrid.

5 La Juno de Alonso Cano fue dada a conocer por PÉREZ SÁNCHEZ, A.E.: «La pintura de Alonso Cano", Figuras e imágenes del Barroco. Estudios sobre el barroco español y sobre la obra de Alonso Cano, Madrid, Fundación Argentaria, 1999, pp. 213-236. Además véase la ficha catalográfica de NAVARRETE PRIETO, B.: «Juno» en HENARES CUÉLLAR, I.: Alonso Cano: Espiritualidad y modernidad artística, Catálogo de la Exposición, Sevilla, Junta de Andalucía, Consejería de Cultura, 2001, pp. 266-267.

6 El San José con el Niño, San Juanito y dos ángeles fue dado a conocer por BUENDíA, J.R.: Op. Cit., pp. 33 y 88, Lám. XIV refiriéndose aquí como procedente de la «colección madrileña de Adanero», y más tarde pasó a formar parte de los fondos de la galería Caylus Anticuario, S. A, véase GUTIÉRREZ PASTOR, I.: «San José con el Niño» en AA.VV.: Tres siglos de pintura, Catálogo de la Exposición, Madrid, Caylus, 1995, pp. 114-117 el mismo año de su definitivo ingresó en el Museo de Bellas Artes de Asturias. Recientemente hemos localizado una copia en la Iglesia-Catedral de Baeza, Jaén, que perteneció a la colección del Seminario hasta 1978.

7 Tasación de los bienes de Margarita Cajés realizado por José Antolínez el 7 de agosto de 1657 citado por AGULLÓ Y COBO, M.: Más noticias sobre pintura madrileña de los siglos XVI y XVII, Madrid, Ayuntamiento, 1981, pág. 35. En el inventario se citan cuatro lienzos mitológicos atribuidos al pincel de Cano: una Fábula de Ícaro, Venus y Cupido, Palas y Apolo. 


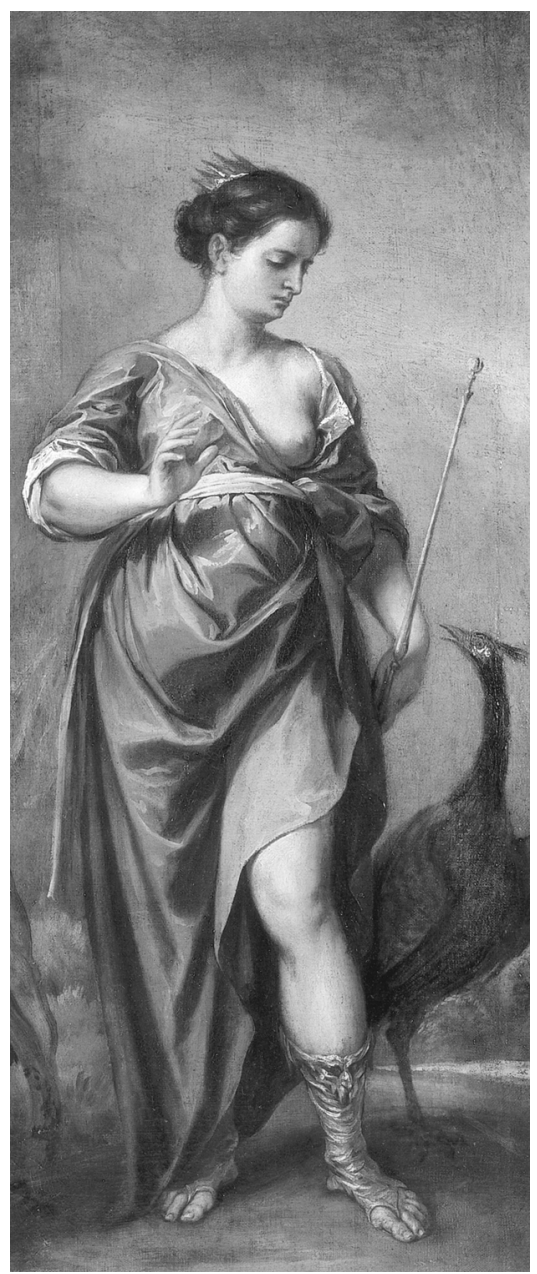

Fig. 1. Alonso Cano, Juno, Colección particular, Madrid.

El segundo documento en importancia hace referencia a la almoneda de las pinturas de Don José de Cisneros, viudo de la Cajés, celebrada en Madrid en 1665 en el que figuran «dos entrepuertas de una figura en cada uno de vara y media de Alto y tercia de ancho con marcos negros (que) representan vna diosa en treynta ducados... y la otra que es un Apolo en veinte Ducados" ${ }^{8}$. Finalmente, el docu-

8 Tasación de los bienes de José de Cisneros realizado por los pintores Mateo Gallardo y Bernardo de Prádano el 11 de septiembre de 1665 citado por AA.VV.: Corpus Alonso Cano: documentos y textos, Madrid, Secretaría de Estado para la Cultura, 2001, p. 447. 


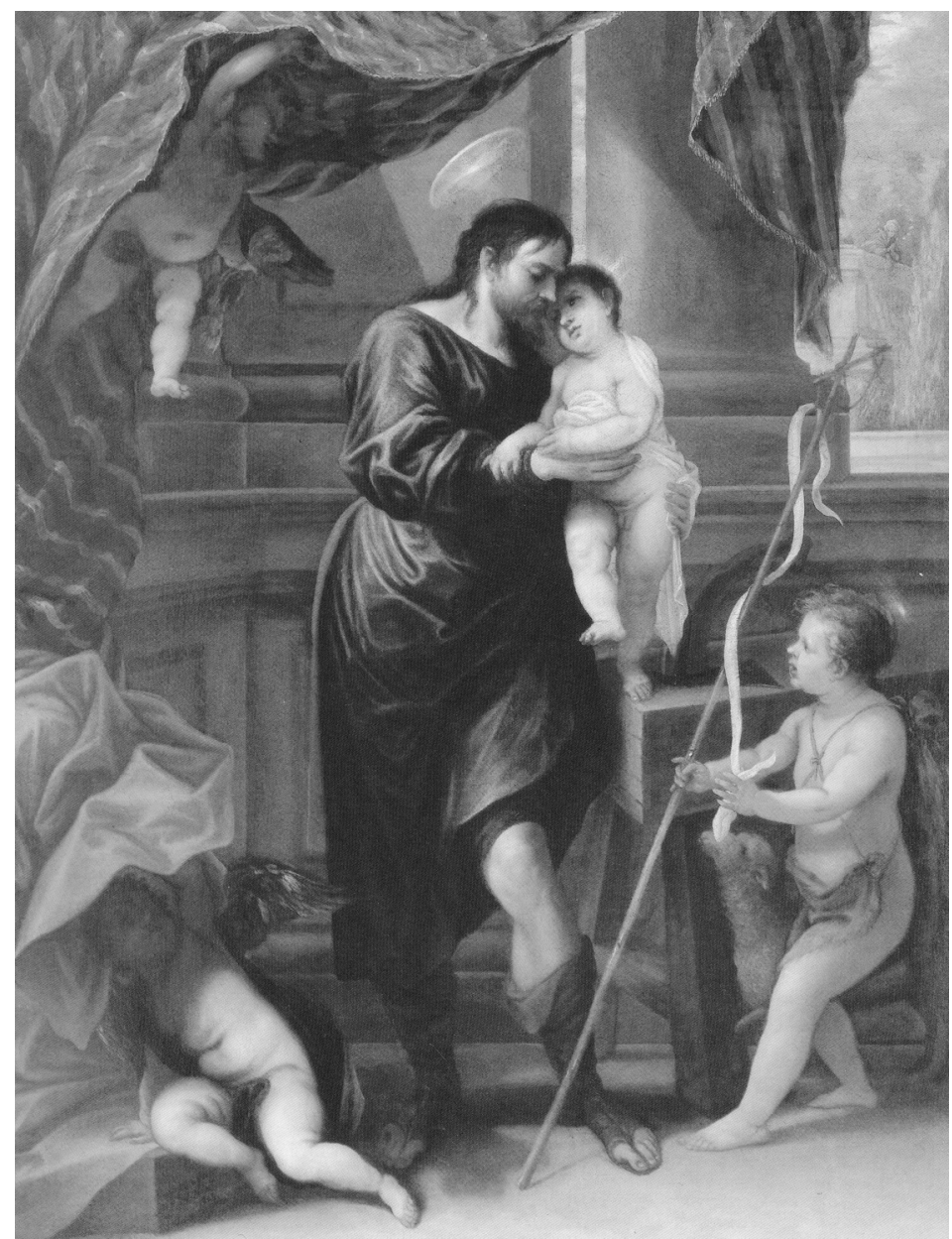

Fig. 2. Juan Antonio de Frías y Escalante, San José con el Niño, San Juanito y dos ángeles, Museo de Bellas Artes de Asturias, Oviedo.

mento expresa el nombre del comprador, la descripción de la obra y su precio de adjudicación: «remataronse en Juan Antonio de frias y escalante. Las pinturas de vara y media de Alto y bara y quarta de ancho de cupido y dos ninfas con marco negro = Y las dos entrepuertas de Vna figura en cada Vno de vara y media de alto y terçia de Ancho con marcos negros Las Una dellas es una diosa y la otra un apolo todos tres en quatrocientos y quarente Reales de vellon»9.

9 Idem, pág. 447. 
En este punto hay tres aspectos que atraen poderosamente nuestra atención, por un lado, como en las dos últimas citas se ha sustituido la palabra «Pallas» por el de «vna diosa» - más genérico e impreciso— mientras que la denominación a su pareja «Apolo» ha permanecido inalterable, y en segundo lugar, la identidad de dimensiones ${ }^{10}$ entre las medidas de la Juno y lo descrito en el inventario, y finalmente el nombre del ávido comprador y propietario de tres de las cuatro escenas mitológicas de Cano, el pintor Juan Antonio de Frías y Escalante.

Más inquietante aún, y lo que demuestra definitivamente que la Juno perteneció a Escalante es la identidad entre la silueta de la diosa y el San José con San Juanito y dos ángeles del Museo de Bellas Artes de Asturias. En efecto, Escalante a lo largo de su carrera abordó el tema de San José con el Niño al menos tres veces ${ }^{11}$ (Colección Strömfeld, Estocolmo; Museo del Ermitage, San Petesburgo; Museo de Bellas Artes de Asturias, Oviedo) siempre evocando modelos de Alonso $\mathrm{Cano}^{12}$, pero hasta ahora no había sido señalada ninguna fuente tan directa para interpretar la obra del pintor cordobés y, en este caso, no ofrece duda alguna que la Juno de Alonso Cano es la fuente seguida directamente por el pintor.

Aunque las diferencias estilísticas son obvias pero no lejanas si tenemos en cuenta la pincelada vibrante y colorista del Racionero, la similitud entre ambas composiciones es evidente en la disposición general del cuerpo, tanto en la pose helicoidal que asciende desde la hercúlea pierna semidesnuda hasta el hombro, como en el perfil del rostro. De este modo Escalante ha transformado un personaje profano de manifiesta sensualidad por otro sacro, sin renunciar a un modelo de inspiración clásica ${ }^{13}$.

Otro aspecto a considerar es la fecha propuesta para el lienzo de la Juno. Si el primer inventario con la tasación de los bienes de Margarita Cajés es de 1657 es

10 Las dimensiones descritas primero en el inventario de 1657, y luego en la almoneda de 1665 indican que la supuesta diosa y su pareja Apolo miden «vara y media de alto y terçia de Ancho" (> $120 \mathrm{x}$ $>30 \mathrm{~cm}$.) estando muy próximas a las medidas exactas de la Juno (105 x $45 \mathrm{~cm}$.).

11 El San José con el Niño de la colección Strömfeld de Estocolmo fue dado a conocer por MÉNDEZ CASAL, A.: «La pintura antigua española en Escandinavia», Revista Española de Arte, núm. 5 (1936), Lám. XIX y el ejemplar del Museo del Ermitage de San Petersburgo por PÉREZ SÁNCHEZ, A.E: Pintura barroca en España. 1600-1750, Madrid, Manuales de Arte Cátedra, 1992, pág. 312.

12 WETHEY, H.E.: Alonso Cano: pintor, escultor y arquitecto, Madrid, Alianza, 1986, p. 138 fue el primero en relacionar el San José con el Niño de la colección Strómfeld de Estocolmo con la homónima obra pintada por Cano hacia 1646 de la colección Masaveu.

${ }_{13}$ Para un estudio pormenorizado de las fuentes formales en la obra de Alonso Cano véase NAVARRETE PRIETO, B. y SALORT PONS, S.: «El saber de un artista: fuentes formales y literarias en la obra de Alonso Cano" en HENARES CUÉLLAR, I.: Alonso Cano: espiritualidad y modernidad artística, Op. Cit., pp. 129-151. Benito Navarrete fue el primero en relacionar la Juno con una estampa de la Lucrecia de Marco Antonio Raimondi, esencialmente en el modo de tratar tanto el perfil del rostro como el desnudo del pecho, véase NAVARRETE PRIETO, B.: «Juno» en HENARES CUÉLLAR, I.: Op. Cit., pp. 266-267. 
obligado pensar que la Juno de Alonso Cano es anterior a esa fecha ${ }^{14}$. En efecto, la primera etapa madrileña del maestro granadino comprende los años 16381651, justo antes de su primera estancia en Granada entre 1652-1657, lo que llevaría a situar el lienzo de Cano en la década de los 40 cuando su entrada en las colecciones reales supuso un giro decisivo en su pintura, ahora más colorista y vibrante.

Queda, pues, demostrado por la documentación y con un ejemplo bien significativo cómo la enigmática Juno fue finalmente adquirida por Escalante quien suponemos que la contemplaría una y otra vez en la intimidad del hogar hasta llevarla de nuevo al lienzo, esta vez bajo la portentosa y enérgica figura de San José con el Niño en rendido homenaje al mejor arte del siempre genial Alonso Cano.

${ }^{14}$ AGULLÓ Y COBO, M.: Op. Cit., pág. 35. 